\title{
The Development and Characterization of a Cotton-Chitosan Composite for Lead Removal from Water
}

\author{
Diana Alonso-Segura 1,* Luis Hernández-García ${ }^{2} \mathbb{D}$, Jorge Menchaca-Arredondo ${ }^{3} \mathbb{D}$, Mario Sánchez $^{4}$, \\ Belén Chamorro-Garza ${ }^{2}$ and Raquel Garza-Hernández ${ }^{4}$
}

1 Biotechnology Engineering Division, Universidad Tecnológica de Corregidora, Carretera Estatal 413, Sta. Barbara Km. 11.2, Coroneo 76900, Mexico

2 Instituto Tecnológico de Nuevo León, Av. de la Alianza 507, Parque de Investigación e Innovación Tecnológica 66628, Mexico; jose.luis.hernandez@itnl.edu.mx (L.H.-G.); bchgarza@gmail.com (B.C.-G.)

3 Facultad de Ciencias Físico Matemáticas, Universidad Autónoma de Nuevo León, Av. Universidad s/n, San Nicolás de los Garza 66455, Mexico; jorge.menchacarr@uanl.edu.mx

4 Centro de Investigación en Materiales Avanzados, Alianza Norte 202, Parque de Investigación e Innovación Tecnológica 66628, Mexico; mario.sanchez@cimav.edu.mx (M.S.); raquel.garza@cimav.edu.mx (R.G.-H.)

* Correspondence: diana.alonso@utcorregidora.edu.mx

check for updates

Citation: Alonso-Segura, D.; Hernández-García, L.

Menchaca-Arredondo, J.; Sánchez, M. Chamorro-Garza, B.

Garza-Hernández, R. The

Development and Characterization of a Cotton-Chitosan Composite for Lead Removal from Water. Polymers 2021, 13, 2066. https://doi.org/ $10.3390 /$ polym 13132066

Academic Editor: Iolanda De Marco

Received: 15 May 2021

Accepted: 20 June 2021

Published: 23 June 2021

Publisher's Note: MDPI stays neutral with regard to jurisdictional claims in published maps and institutional affiliations.

Copyright: (c) 2021 by the authors. Licensee MDPI, Basel, Switzerland. This article is an open access article distributed under the terms and conditions of the Creative Commons Attribution (CC BY) license (https:/ / creativecommons.org/licenses/by/ $4.0 /)$
Abstract: Heavy metals in water are a serious environmental problem due to their accumulation and toxicity; there are several processes we can use to address this issue, but adsorption is the most popular due to its simplicity and efficiency. Polysaccharides such as cellulose have received attention as adsorbents for heavy metals, and cotton-chitosan composites (CCs) were developed here with nontoxic reagents such as carboxylic acids as crosslinkers and $\mathrm{NaH}_{2} \mathrm{PO}_{4}$ as a catalyst to achieve chitosan covalent crosslinkage into oxidized cotton textiles with $\mathrm{H}_{2} \mathrm{O}_{2}$. The composites were characterized by fourier-transform infrared spectroscopy (FTIR), elemental analysis (EA), X-ray photoelectron spectroscopy (XPS), atomic-force and scanning electron microscopy (AFM and SEM), and tensile strength; the adsorption of lead ions $(\mathrm{Pb})$ was evaluated with cotton-chitosan composites and quantified by microwave plasma atomic emission spectroscopy (MP-AES). The composites showed a maximum incorporation of chitosan of $27.62 \mathrm{mg}$ per gram of cotton textile. A tensile strength analysis of the composite showed a Young's modulus approximately $1 \mathrm{MPa}$ higher than that of cotton textile. The adsorption of lead ions with composites in an aqueous solution at $\mathrm{pH} 5$ and $25{ }^{\circ} \mathrm{C}$ was circa $74 \%$ after $6 \mathrm{~h}$ of contact, as determined by MP-AES. This work is an approach to demonstrate the potential of these polysaccharides, modified by "green" procedures to remove pollutants from water.

Keywords: chitosan; cotton fiber; composite; lead

\section{Introduction}

Heavy metals in water are a severe environmental problem that directly affects human health even at very low concentrations; most of them are considered persistent, nonbiodegradable, and toxic, and must be removed; hence, an enormous amount of research into how to clean water at a lower cost and with less energy is needed. Many methods have been used to remove metals from water, such as ion exchange, chemical precipitation, filtration, electrolytic processes, solvent extraction, adsorption, and biosorption [1-5]. Adsorption is one of the most popular methods due to its simplicity, low cost, efficiency, the regeneration capacity of the adsorbent, no sludge generation, and simple recovery; however, some adsorption mechanisms are still not fully understood [3,6-8]. Polysaccharides such as cellulose, cellulose derivates, cotton textiles, and chitosan have received significant attention over the last two decades because they are convenient for heavy metal adsorption and are environmentally friendly materials [1,3,5,9-15].

Cellulose is easily obtained from nature; it is hydrophilic and has good reaction properties, so is a very good option to use as an adsorbent, or it can be functionalized to 
enhance its adsorption performance $[5,6,11,12]$. In this matter, cellulose extracted from jute fiber was modified with methyl acrylate/acrylonitrile monomers by a free radical method to obtained poly(methyl acrylate)-grafted cellulose and/or poly(acrylonitrile)grafted cellulose and used for the removal of heavy metal ions from wastewater [1]; or for instance, Yu et al. designed a hyperbranched polyamide and synthesized a dialdehyde cellulose to be crosslinked together by a reductive amination. The adsorption capacity of $\mathrm{Cu}$ (II) of this functionalized cellulose was $137 \mathrm{mg} / \mathrm{g}$ due to the increased number of active sites on the developed material [13].

On the other hand, chitosan, the deacetylated form of the polysaccharide chitin, mainly found in the exoskeleton of crustaceans, is versatile, nontoxic, and has a good adsorption capacity due to the presence of amino and hydroxyl groups in the polymer matrix that act as active sites [10-12]. Nonetheless, chitosan's stability in acidic environments limits its applications, as do its low surface area and poor mechanical and thermal properties; therefore, crosslinking processes to improve it have been studied [10-12,14-16]. The chemical modification of chitosan or its chemical fixation by covalent crosslinking into cellulose or other polymer matrices may improve the endurance and efficiency of the resultant composite, as reported by Yang et al., who crosslinked carboxymethylated chitosan and nanocrystalline cellulose through a Schiff base reaction to obtain a reusable adsorbent over a wide $\mathrm{pH}$ range [15].

The chemical fixation of chitosan and its covalent crosslinkage may involve toxic reagents that have several constraints such as the mechanical properties of the matrix, fiber degradation, and above all, the release of toxic and irritant compounds during the elaboration process and throughout storage $[17,18]$. Polycarboxylic acids have been used as an alternative to poisonous crosslinkers [14,19-21]. Hence, the use of citric acid and low-toxicity oxidizing agents, such as potassium permanganate, sodium hypophosphite, or even a food-grade reagent such as monosodium phosphate, has been shown to promote adequate chemical fixation between chitosan and cellulose [20-23].

Hydrogen peroxide $\left(\mathrm{H}_{2} \mathrm{O}_{2}\right)$, an environmentally friendly reagent, has been used in high concentrations (above $1 \mathrm{M}$ ) to modify the crystalline structures of polysaccharides, changing their physical and chemical properties through the formation of free radicals, which attack the glycosidic linkages of polysaccharides [24-26].

In this work, hydrogen peroxide was used for the pretreatment of cotton textiles by oxidation; citric acid (CA) and butanetetracarboxylic acid (BTCA) were used as crosslinkers, with sodium phosphate as a catalyst, to attain chitosan covalent crosslinkage into cotton textiles. Hence, environmentally friendly composites were developed herein, based on an easy, cheap, and low-energy method, to be used for heavy metal adsorption in water. In this case, we evaluated lead adsorption at trace levels in water, as lead has been identified as one of the toxic elements that, in the aqueous phase, accumulate across the food chain and can cause serious diseases such as renal failure, brain damage, and cancer [14]. Therefore, this work is an attempt to demonstrate the potential of "green" composites based on chitosan-cotton textiles that help to remove traces of toxic elements, can be reused and eventually biodegrade due to their natural composition.

\section{Materials and Methods}

Chitosan (deacetylation degree $\geq 75 \%$ ) and butanetetracarboxylic acid (BTCA) were purchased from Sigma-Aldrich (San Luis, MO, USA); cotton textiles were purchased from La Parisina Fabric Store (Mexico City, Mexico); $\mathrm{H}_{2} \mathrm{O}_{2}$ at $35 \% v / v$ food grade was from Je Chemistry (Monterrey, Mexico); citric acid (CA) and sodium phosphate $\left(\mathrm{NaH}_{2} \mathrm{PO}_{4}\right)$ were from Fermont (Monterrey, Mexico); and acetic acid and nitric acid $\left(\mathrm{HNO}_{3}\right)$ were purchased from JT Baker (Allentown, PA, USA). All reagents were used as supplied. The UV light lamp UVGL-58 was from Ultra-Violet Products (Jena, Germany). 


\subsection{Composite Development}

Cotton-chitosan composites (CCs) were prepared by the pretreatment of cotton textiles with $\mathrm{H}_{2} \mathrm{O}_{2}$, followed by a crosslinkage reaction through citric acid or butanetetracarboxylic acid with chitosan and $\mathrm{NaH}_{2} \mathrm{PO}_{4}$ as a catalyst. All the composites developed herein are summarized in Table 1 and described below: aqueous solutions of chitosan $(1.5 \% w / v)$, one with $4 \% w / v$ of citric acid (CA), and another with $4 \% w / v$ of butanetetracarboxylic acid (BTCA), were prepared. Both polycarboxylic acids were used as solvents for chitosan and as crosslinkers for the composites. Pieces of cotton textile of approximately $15 \mathrm{~cm}^{2}$ each were pretreated and submerged in $\mathrm{H}_{2} \mathrm{O}_{2}$ for $40 \mathrm{~min}$; after that, excess peroxide was removed with distilled water and the samples were dried overnight.

Table 1. Composites' formulation.

\begin{tabular}{ccccc}
\hline Composite & $\left.\mathbf{H}_{\mathbf{2}} \mathbf{O}_{\mathbf{2}} \mathbf{( 3 5 \%} \boldsymbol{v} / \mathbf{v}\right)$ & $\mathbf{C A}$ & $\mathbf{B T C A}$ & $\mathbf{N a H}_{\mathbf{2}} \mathbf{P O}_{\mathbf{4}}$ \\
\hline 1 & $40 \mathrm{~min}$ & $4 \% w / v$ & - & - \\
2 & $40 \mathrm{~min}$ & - & $4 \% w / v$ & - \\
3 & $40 \mathrm{~min}$ & $4 \% w / v$ & - & $2.3 \% w / v$ \\
4 & $40 \mathrm{~min}$ & - & $4 \% w / v$ & $2.3 \% w / v$ \\
\hline
\end{tabular}

Next, the pretreated cotton textile pieces (with hydrogen peroxide) were immersed into a chitosan aqueous solution with CA or BTCA. After that, 2.3\% $w / v$ of $\mathrm{NaH}_{2} \mathrm{PO}_{4}$ was added to the mixture, which was heated to $70{ }^{\circ} \mathrm{C}$ for $5 \mathrm{~min}$ in order to obtain the composites; these were then removed from the solution and dry-cured in a thermal oven at $130^{\circ} \mathrm{C}$ for $3 \mathrm{~min}$, as reported before [21]. CCs were dried at room temperature, washed with commercial ionic soap, rinsed with distilled water, followed by a wash of acetic acid solution $(0.1 \mathrm{M})$ in order to remove noncrosslinked chitosan from the composites, rinsed with distilled water several times until the acidic smell was gone, dried overnight, and weighed prior to analyses.

\subsection{Composites' Characterization}

An elemental analysis to quantify the nitrogen incorporated into the composites was conducted on a CHN/O Perkin Elmer 2400 Series II (Shelton, CT, USA).

Fourier transformed infrared analysis (FT-IR) of the composites, as well as of the cotton textiles, was conducted on a Nicolet iS10 (Waltham, MA, USA) with an attenuated total reflectance (ATR) accessory with a diamond tip. Each sample was scanned 64 times at a wavelength of $4000-400 \mathrm{~nm}$.

Tensile testing was carried out on a MTS TestSuite ${ }^{\mathrm{TM}}$ TWElite (Eden Prairie, MN, USA) at a speed of $4.23 \mathrm{~mm} / \mathrm{s}$; composites and cotton textiles were cut into strips of $100 \pm 1.5 \times 15.09 \pm 1.24 \mathrm{~mm}$ with an average thickness of $0.4 \pm 0.25 \mathrm{~mm}$, and samples were tested by triplicate to obtain the average value.

The composites and cotton textiles were observed using a scanning electron microscope Nova NanoSEM200 (FEI, Hillsboro, OR, USA) at low vacuum, using a low vacuum detector (LV), and a NT-MDT NTEGRA Prima AFM at room temperature, with a RTESPA probe (Bruker, Mexico City, Mexico) of spring constant $\mathrm{k}=40 \mathrm{~N} / \mathrm{m}$ in intermittent contact mode. Images of height, deflection, and phase were obtained; $100 \times 100$ and $20 \times 20 \mu \mathrm{m}^{2}$ image sizes were captured systematically for each sample in the three different regions. They were analyzed with Nova 3.1 to obtain the average roughness and morphological aspect of the composites.

\subsection{Lead, $\mathrm{Pb}(\mathrm{II})$, Adsorption-Desorption Determination}

Adsorption and desorption experiments related to lead removal from water were determined twice in batches. The $\mathrm{Pb}$ ion solutions were analyzed with an Agilent MPAES 4200 microwave plasma-atomic emission spectrometer (Santa Clara, CA, USA), at a wavelength of $368.34 \mathrm{~nm}$ and a nebulizer pressure of $0.95 \mathrm{~L} / \mathrm{min}$. The adsorption capacity 
$q_{e}(\mathrm{mg} / \mathrm{g}), \%$ adsorption of $\mathrm{Pb}$, and \% desorption were calculated according to the following Equations (1)-(3) [1,12,14]:

$$
\begin{gathered}
q_{e}=\frac{\left(C_{0}-C_{e}\right) V}{m} \\
\% \text { Adsorption }=\frac{\left(C_{0}-C_{e}\right)}{C_{0}} 100 \\
\% \text { Desorption }=\frac{C_{\text {ion desorbed by eluent }}}{C_{\text {initial of ion adsorbed on adsorbent }}} 100
\end{gathered}
$$

where $C_{0}$ and $C_{e}(\mathrm{mg} / \mathrm{L})$ are the initial and equilibrium concentrations of lead, $V(\mathrm{~L})$ is the volume of solution, and $m(\mathrm{~g})$ is the mass of composite used as adsorbent.

Lead adsorption by CCs was evaluated, at $\mathrm{pH} 5$, with $\mathrm{Pb}$ in $\mathrm{HNO}_{3}$ at $3 \% v / v$ and $\mathrm{Pb}$ in $\mathrm{H}_{2} \mathrm{O}_{2}$ at $4 \% v / v$ at $25{ }^{\circ} \mathrm{C}$; the $\mathrm{pH}$ was adjusted with $\mathrm{NaOH} 0.1 \mathrm{~N}$ or with $\mathrm{HNO}_{3}$ $0.1 \mathrm{M}$. Then, $250 \mathrm{mg}$ of dried composites were weighed and submerged into $100 \mathrm{~mL}$ of $\mathrm{Pb}$ solution with an initial concentration, $C_{0}$, of $40 \mathrm{mg} / \mathrm{L}$ for $6 \mathrm{~h}$ at room temperature. In order to analyze the metal ion concentration adsorbed, aliquots were taken every $2 \mathrm{~h}$.

To elute adsorbed lead ions, composites from adsorption determinations were submerged in $100 \mathrm{~mL}$ of nitric acid $\left(\mathrm{HNO}_{3}\right)$ solution, $0.1 \mathrm{M}$, for $6 \mathrm{~h}$ at room temperature and agitation $(75 \mathrm{rpm})$, every $2 \mathrm{~h}$ aliquots were taken and analyzed with MP-AES.

\subsection{X-ray Photoelectron Spectroscopy (XPS)}

X-ray photoelectron spectroscopy was used to determine the surface composition and chemical states of the composites before and after the adsorption determinations. The measurements were performed in an X-ray spectrometer (Thermo Scientific Escalab 250 $\mathrm{Xi}$; Santa Clara, CA, USA). The photoelectrons were generated with monochromatic Al $\mathrm{K} \alpha(1486.7 \mathrm{eV})$ as the $\mathrm{X}$-ray source with a line width of $0.20 \mathrm{eV}$. The ultra-high vacuum analysis chamber was kept at a base pressure of $<4 \times 10^{-8} \mathrm{~Pa}$. The electrons were detected using a hemispherical analyzer with a pass energy of $20 \mathrm{eV}$. The relevant core levels $\mathrm{C} 1 \mathrm{~s}$, $\mathrm{N} 1 s, \mathrm{O} 1 s$, and $\mathrm{Pb} 4 f$ were considered to quantify the elemental atomic contents, using the sensitivity factors from the instrument database. Corrections to the shift in the binding energy were made by fixing the energy of the C1s peak, from adventitious carbon in the films, at $284.8 \mathrm{eV}$. The fitting procedure was an iterative process whereby all the peaks were fitted using the AAnalyzer ${ }^{\circledR}$ (CINVESTAV-Queretaro, Santiago de Querétaro, Mexico) peak fitting software.

\section{Results}

\subsection{Composites' Characterization}

\subsubsection{Elemental Analysis}

The results of the elemental analysis indicated that the composites, after being subjected to several washes, presented a high nitrogen content; this was attributed to the crosslinked chitosan into cotton textiles using either citric acid or butanetetracarboxylic acid; the nitrogen determinations are presented in Table 2.

Table 2. Chitosan crosslinked into the composites developed herein.

\begin{tabular}{cc}
\hline Composite & $\mathbf{m g}_{\text {chitosan }}$ to gcomposite $^{*}$ \\
\hline 1 & $13.56 \pm 2.00$ \\
2 & $22.60 \pm 1.81$ \\
3 & $20.13 \pm 0.87$ \\
4 & $27.62 \pm 5.03$
\end{tabular}

* Results are the mean of three determinations and their standard deviations.

The composites where $\mathrm{H}_{2} \mathrm{O}_{2}$ was used with CA or with BTCA as crosslinkers displayed the highest chitosan incorporation of $20.13 \mathrm{mg} / \mathrm{g}_{\text {composite }}$ and $27.62 \mathrm{mg} / \mathrm{g}_{\text {composite }}$, composites 3 and 4 , respectively. When a catalyst $\left(\mathrm{NaH}_{2} \mathrm{PO}_{4}\right)$ was not used, the chi- 


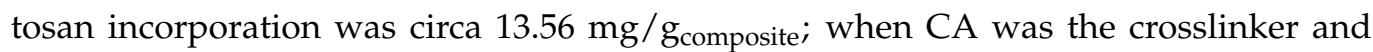
$22.6 \mathrm{mg} / \mathrm{g}_{\text {composite }}$ with BTCA (composites 1 and 2, Table 2), there was almost $5 \mathrm{mg} / \mathrm{g}_{\text {composite }}$ less than when the catalyst was used.

\subsubsection{Fourier Transform Infrared Spectra}

The FT-IR spectra of composites 3 and 4 show those bands related to the primary amine group that are slightly visible at $1560 \mathrm{~cm}^{-1}$; the peaks at 2927 and $2839 \mathrm{~cm}^{-1}$ are attributed to $\mathrm{C}-\mathrm{H}$ stretching of the alkyl group of cellulose as well as from the chitosan (Figure 1). Also, the presence of a $\mathrm{C}=\mathrm{O}$ ester stretching band at $1705 \mathrm{~cm}^{-1}$ is more intense for composite 3 when CA and hydrogen peroxide were used for its elaboration, which indicates that the covalent attachment of chitosan into cotton textiles was by an ester bond formation, as reported elsewhere [21].

\subsubsection{Tensile Strength}

The tensile strength properties of the composites developed in this work show that the use of $\mathrm{H}_{2} \mathrm{O}_{2}$ as a pretreatment for cotton textiles reduces its elasticity, but with chitosan crosslinkage, there is an increase in the tensile strength observed. The stronger composite (composite 4), the one with the higher chitosan concentration crosslinked, has a modulus of $67.1 \pm 3.3 \mathrm{MPa}$, approximately $1 \mathrm{MPa}$ more than the cotton textile used herein. The relationship between the Young's modulus and the strain at the breaking point of composites, as well as from the cotton textiles, are shown in Figure 2, with composite 4 being the one with the smallest strain at the breaking point, and hence the composite with the highest modulus.

\subsubsection{Atomic Force and Scanning Electron Microscopy}

The topographical examination of composites by AFM revealed changes in the textile surface, as shown in Figure 3; these changes are related to chitosan crosslinkage. Cotton textiles presented a rough surface with an average height of circa $1.43 \mu \mathrm{m}$, and these values changed with chitosan incorporation, so the greater the chitosan concentration determined in composites, the smoother the surface analyzed. Composite 4 , which showed almost $27 \mathrm{mg}$ of chitosan for each gram of composite (Table 2), displayed the smoothest surface, with an average height of $77 \mathrm{~nm}$.

In SEM micrographs of composites, pristine cotton textile and cotton textile oxidized with hydrogen peroxide are shown in Figure 4. It can be observed that the oxidized textile (Figure 4 b) look similar to the pristine cotton textile (Figure 4a). Changes in morphology can be observed in the developed composites (Figure $4 \mathrm{c}-\mathrm{f}$ ). Composites presented extra material like lumps, making the surface heterogeneous as well as less even, being more noticeable in micrographs that correspond to composite 3 and 4 (Figure 4e, 4f), which demonstrate chitosan crosslinkage into cotton textile.

\subsection{Lead Adsorption from Water}

The best adsorption capacity is carried out in aqueous solution, as reported in several works at $\mathrm{pH} 5[1,12,14]$, here, it was $75.54 \%$ during the first $2 \mathrm{~h}$ with composite 4 . The higher the chitosan content in the composite, the faster the adsorption, reaching almost $74 \%$ during the first $2 \mathrm{~h}$, with no increases after $6 \mathrm{~h}$ (composite 4 ). This occurred when $\mathrm{PbO}$ was used, but not when $\mathrm{Pb}\left(\mathrm{NO}_{3}\right)_{2}$ was the lead ion source (Figure 5); during the first $2 \mathrm{~h}$ the adsorption percentage was $35 \%$, with the highest adsorption percentage being $74 \%$ for composite 4 after $6 \mathrm{~h}$.

In Figure 6, the amount of $\mathrm{Pb}(\mathrm{II})$ adsorbed $\left(q_{\mathrm{e}}\right)$ is presented. The $\mathrm{PbO}$ solution adsorbed lead ions at circa $6 \mathrm{mg} / \mathrm{g}$ of composite with all composites developed here after the first $2 \mathrm{~h}$ of contact, almost 7 times higher than with a pristine cotton textile. On the other hand, with the solution of $\mathrm{Pb}\left(\mathrm{NO}_{3}\right)_{2}$, after $2 \mathrm{~h}$ only composite 4 adsorbed $2 \mathrm{mg} / \mathrm{g}$, almost 3 times more than cotton textile, and after $6 \mathrm{~h}$ most of the composites $(1,2$, and 3$)$ adsorbed almost 5 times more; composite 4 adsorbed the highest concentration of lead ions. 

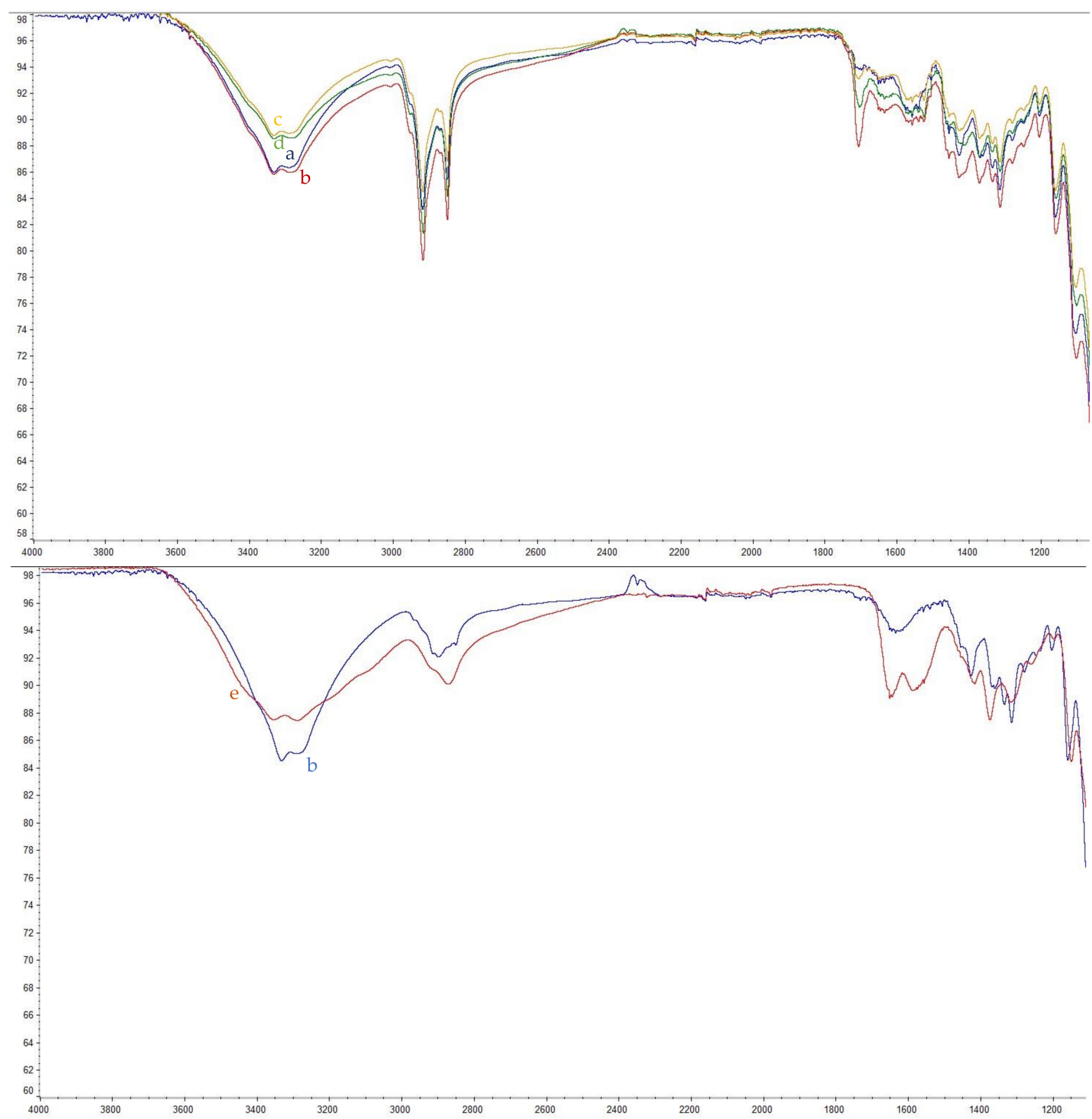

Figure 1. FTIR spectra: (a) composite 4, navy blue; (b) composite 2, red; (c) composite 3, yellow; (d) composite 1, green; (e) chitosan, orange; (f) cotton textile, blue.

\subsection{Lead Desorption from Composites}

Desorption determination was carried out with an acid aqueous solution, where the lead ion of the complexes formed between CCs and lead, proposed in Scheme 1, makes a bond with the $\mathrm{NO}_{3}{ }^{-}$and is eluted out from the CCs, desorbing almost $71.5 \%$ after $2 \mathrm{~h}$ from composite 4 . A plateau was observed at $4 \mathrm{~h}$, and $6 \%$ more lead was desorbed than in a cotton textile after the same time; however, after $6 \mathrm{~h}$, composite 4 adsorbed the lead ions over again. Figure 7 demonstrates the interactions between composite moieties and lead ions presented in Scheme 1. 


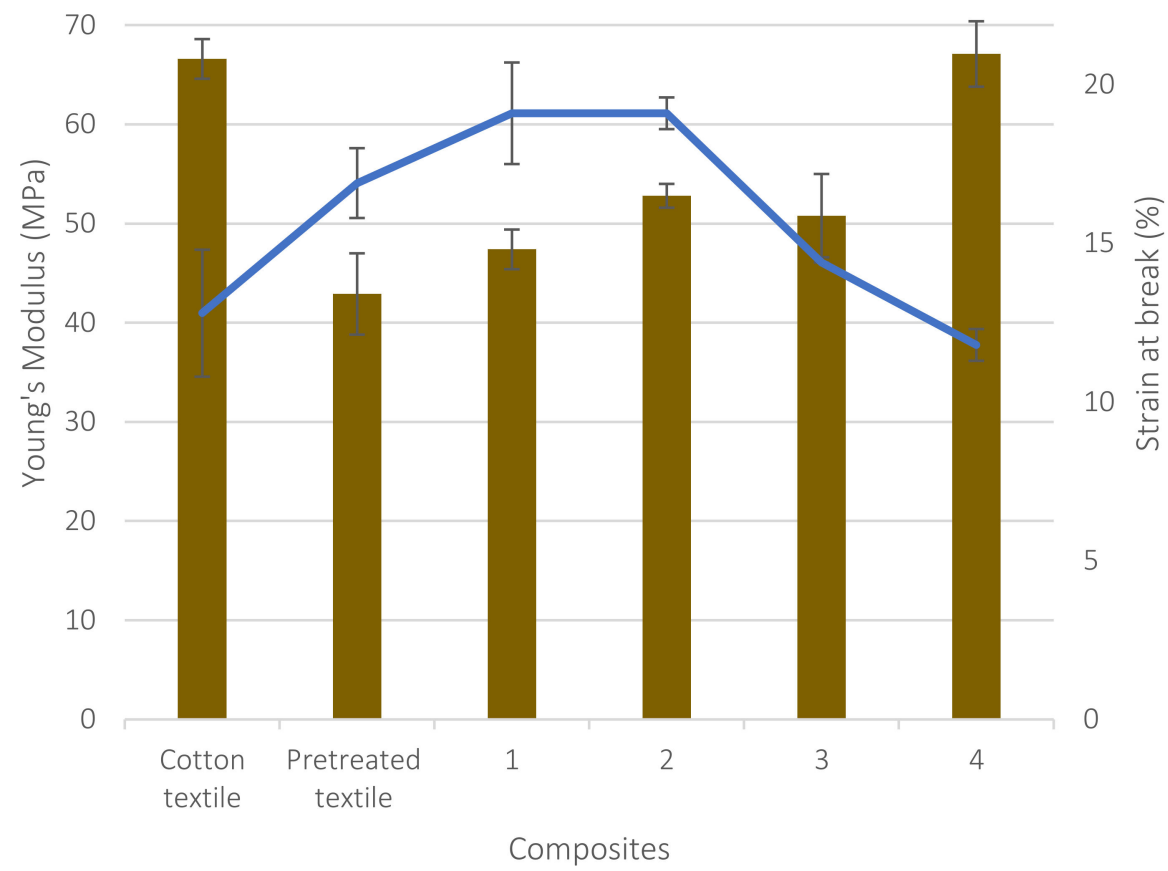

Figure 2. Average tensile strength and strain at the breaking point of cotton textiles, pretreated textiles with $\mathrm{H}_{2} \mathrm{O}_{2}$, and composites.

In the macroscopic structure of the developed composites, it is possible to observe different groups with free electron pairs, in which the metallic ions can have a stereoelectronic interaction. Given the number, geometry, and distance of the hydroxyl groups present in cellulose and chitosan, these give the biopolymer an attractive capacity as a lead adsorbent. Crosslinking agents such as BTCA have sp3 hybridized carbons that provide greater flexibility to the carbonyl groups to trap metal ions. On the other hand, the amino groups of chitosan presumably interact more with metal ions (Scheme 1), because those amino groups behave as a softer base than oxygen according to Pearson's theory [27], which agrees with the data obtained from the elemental analysis, where composite 4 has the highest amount of chitosan and the best adsorption capacity.

\subsection{Surface Analysis by XPS}

The high-resolution spectra corresponding to the $\mathrm{C} 1 \mathrm{~s}, \mathrm{O} 1 \mathrm{~s}, \mathrm{~N} 1 \mathrm{~s}$, and $\mathrm{Pb} 4 f$ core energetic levels of the different composites after the adsorption of lead are shown in Figure 8. The main chemical difference between them is the extra carboxylic group for composites in which BTCA was used as crosslinker (composites 2 and 4), which can be used as a reactive site for the adsorption of lead. The $\mathrm{C} 1 \mathrm{~s}$ spectra region is constituted of three main components. The first peak located at $284.8 \mathrm{eV}$ is attributed to the $\mathrm{C}-\mathrm{H} / \mathrm{C}-\mathrm{C}$ chemical bonds; moreover, the $\mathrm{C}-\mathrm{NH}_{2}$ bond overlapped with this peak [28]. The second peak was centered at $286.3 \mathrm{eV}$ and can be assigned to the $\mathrm{C}-\mathrm{OH}, \mathrm{C}-\mathrm{O}$, and $\mathrm{C}-\mathrm{N}$ bonds [29] The third peak at $288.0 \mathrm{eV}$ corresponds to $\mathrm{O}-\mathrm{C}-\mathrm{O} / \mathrm{N}-\mathrm{C}=\mathrm{O}$, where components such as $\mathrm{C}=\mathrm{O}$ or $\mathrm{O}=\mathrm{C}-\mathrm{O}$ can be overlapped by this peak $[29,30]$. The molecular structure of organic composites only exhibits one kind of nitrogen species $\left(-\mathrm{NH}_{2}\right)$; nevertheless, two inflections were detected in the $\mathrm{N} 1 s$ spectra. A single nitrogen signal was perceived in the pristine cotton textile at $399.9 \mathrm{eV}$, which is attributed to the nonprotonated amine from chitosan [31,32]. An extra component at $401.8 \mathrm{eV}$ was found in the samples when oxidizing agents were used $\left(\mathrm{H}_{2} \mathrm{O}_{2}\right)$. The oxidation of amines is relatively easy; thus, the component found at the higher binding energy was related to the $-\mathrm{NHOH} /-\mathrm{NO}$ groups [33]. 


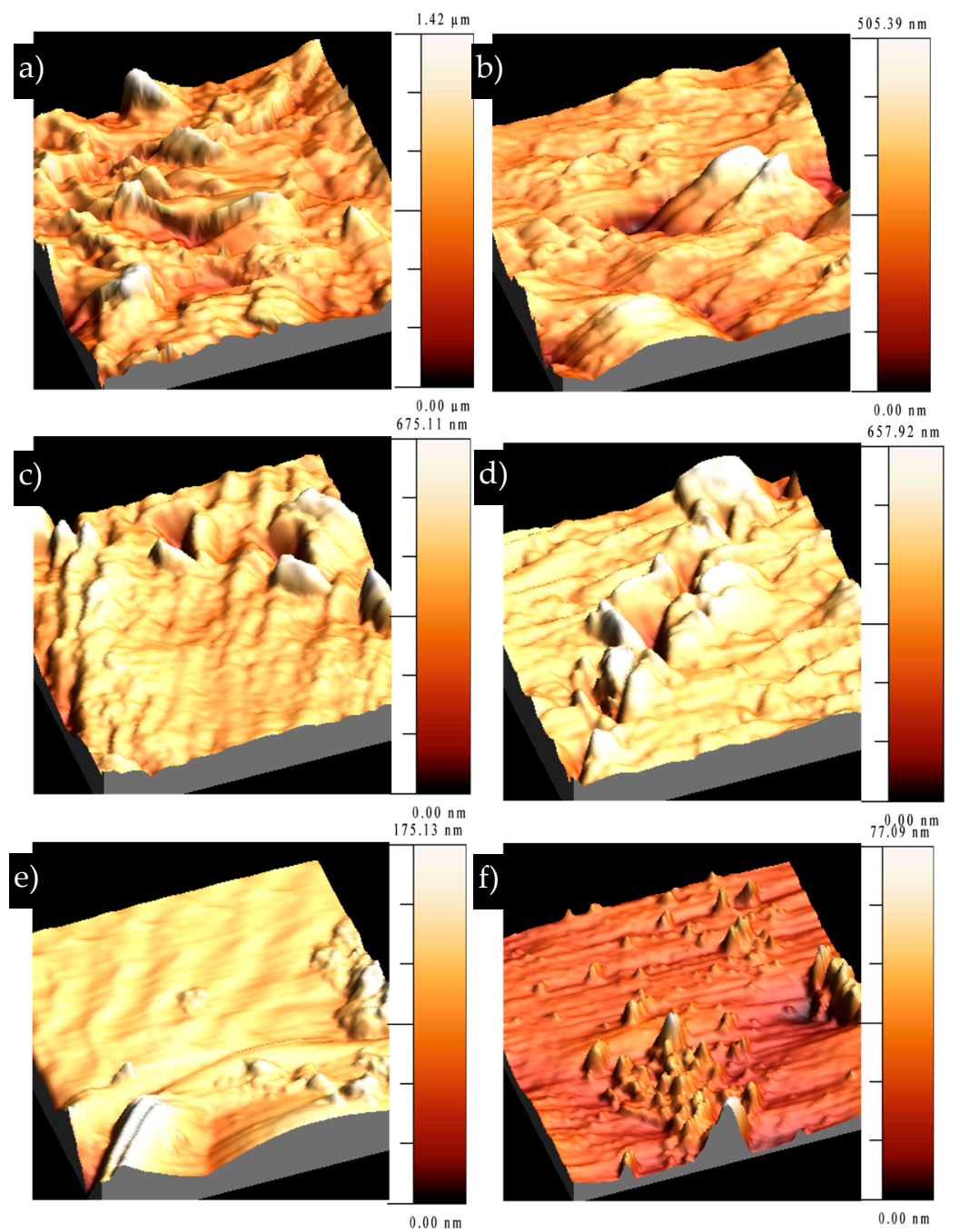

Figure 3. Representative AFM images of (a) cotton textile, (b) pretreated textile with $\mathrm{H}_{2} \mathrm{O}_{2}$, (c) composite 1, (d) composite 2, (e) composite 3, and (f) composite 4.

The detection of some metals at the surface by XPS can be difficult, especially when it is found with a low concentration in a matrix. The adsorption of $\mathrm{Pb}$ at the surface of the composites was possible because the " $4 f$ " orbital has a high sensitivity factor (22.74). The $\mathrm{Pb} 4 f$ region is constituted of $\mathrm{Pb} 4 f_{7 / 2}$ and $\mathrm{Pb} 4 f_{5 / 2}$ core level peaks. The doublet peaks centered at $138.8 \mathrm{eV}$ and $139.8 \mathrm{eV}$ with a spin-orbit splitting of $4.84 \mathrm{eV}$ are associated with the $\mathrm{Pb}-\mathrm{O}$ and $\mathrm{Pb}-\mathrm{NO}_{3}$ bonds, respectively [34]. An extra peak at high binding energy $(140.9 \mathrm{eV})$ was observed only for composite 4 . The spectra for O1s showed three peaks. The peak located at the lower binding energy $(531.1 \mathrm{eV})$ was attributed to $\mathrm{O}-\mathrm{C}$ bonding, which formed due to the adsorption of $\mathrm{CO}_{2}$ from the atmosphere. The $\mathrm{O}-\mathrm{Pb}$ bond is complicated to distinguish because it has been found at $529-530 \mathrm{eV}$, which overlaps with the $\mathrm{O}-\mathrm{C}$ peak $[35,36]$. The peak at $532.7 \mathrm{eV}$ is assigned to the $\mathrm{H}-\mathrm{O}-\mathrm{C}$ and $\mathrm{O}-\mathrm{C}=\mathrm{O}$ bonds $[28,29,37,38]$, which corresponds to all carboxylic and hydroxy groups from the composites. As perceived in the $\mathrm{Pb} 4 \mathrm{f}$ region, there is a component at higher binding energy $(534.2 \mathrm{eV}$ ) only for composite 4 . This peak could be related to a super oxidized species or $\mathrm{Pb}-\mathrm{SO}_{4}[35]$.

Table 3 shows the percentages of the relative atomic concentrations of all elements found in the samples. The atomic ratio $\mathrm{O} / \mathrm{C}$ for the composites has been found to be around of $0.25-0.32$. The atomic concentrations obtained by XPS revealed that crosslinking between cotton textile, chitosan, and BTCA or CA reagents occurred due to the $\mathrm{O} / \mathrm{C}$ atomic ratio, which increased from 0.25 to 0.32 . The adsorption of lead in all composites developed both 
BTCA and CA (composites 1-4) was higher than with pristine cotton textile. Particularly with those with BTCA, both composites 2 and 4 exhibited the highest lead content, proving that the extra carboxyl group is helpful for metal adsorption.

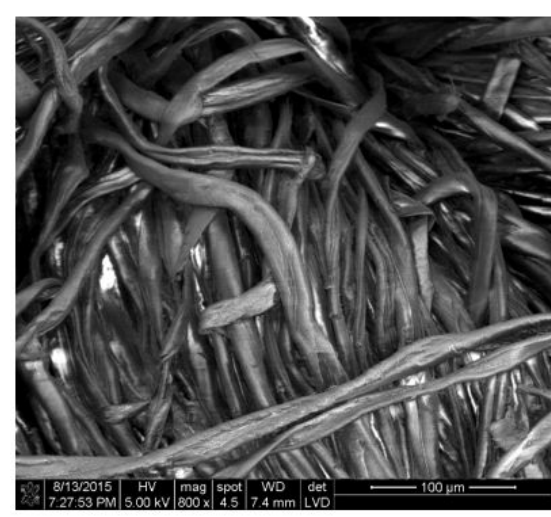

(a)

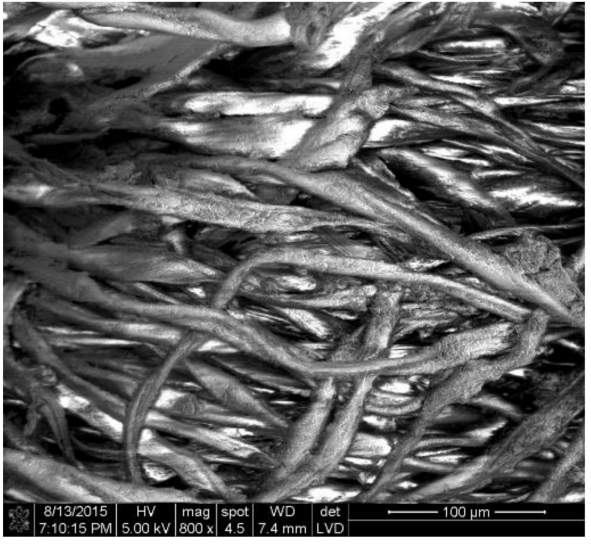

(c)

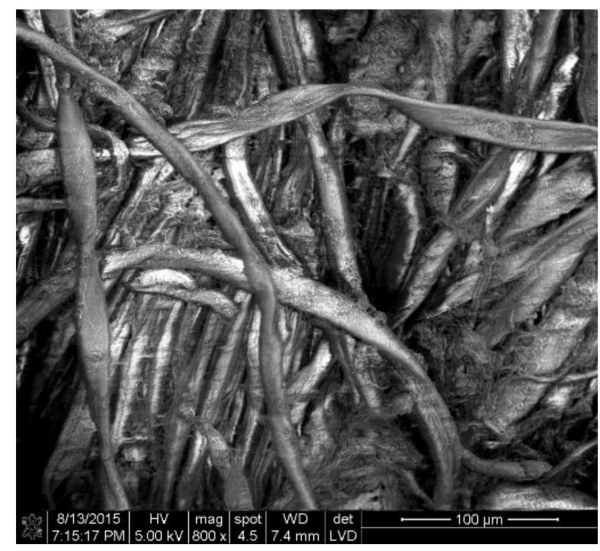

(e)

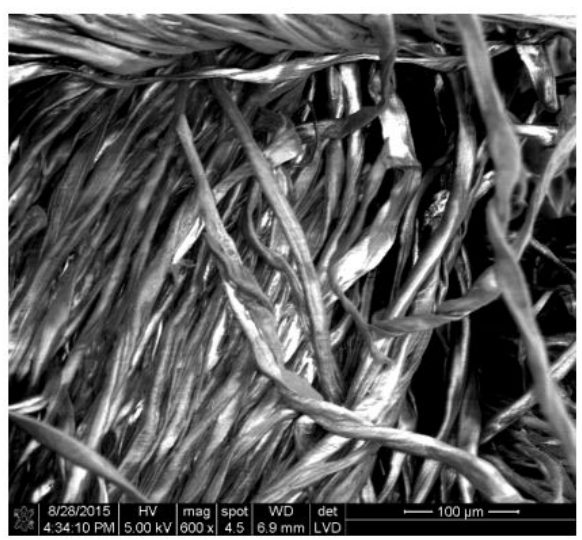

(b)

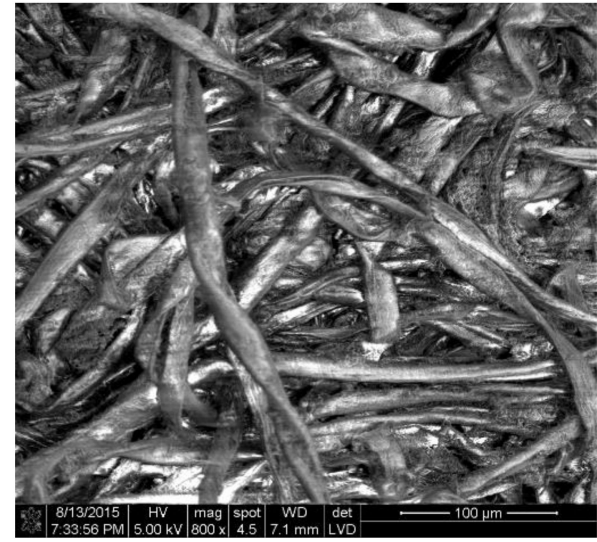

(d)

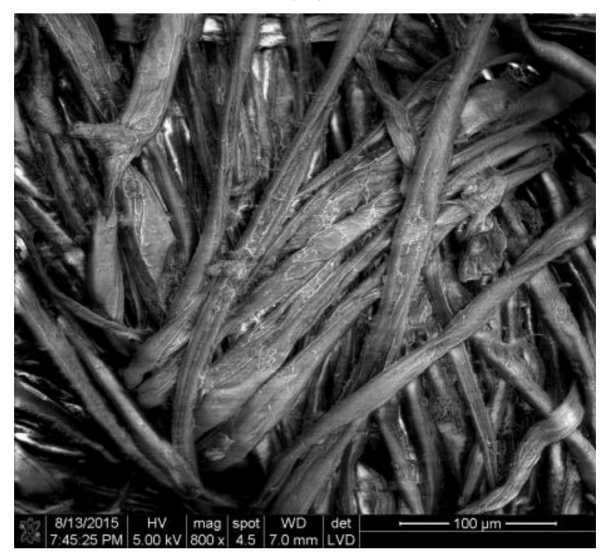

(f)

Figure 4. SEM images of (a) cotton textile, (b) pretreated textile with $\mathrm{H}_{2} \mathrm{O}_{2}$, (c) composite 1, (d) composite 2, (e) composite 3, and (f) composite 4. 


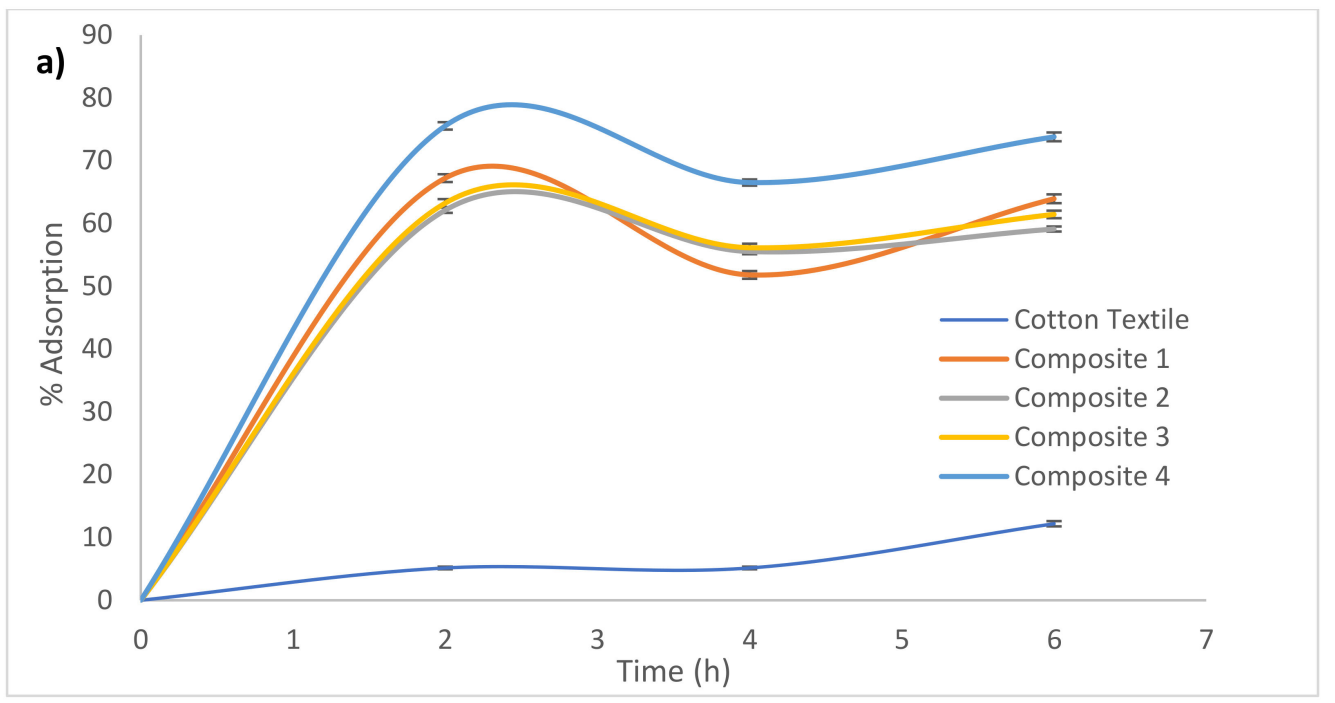

b)

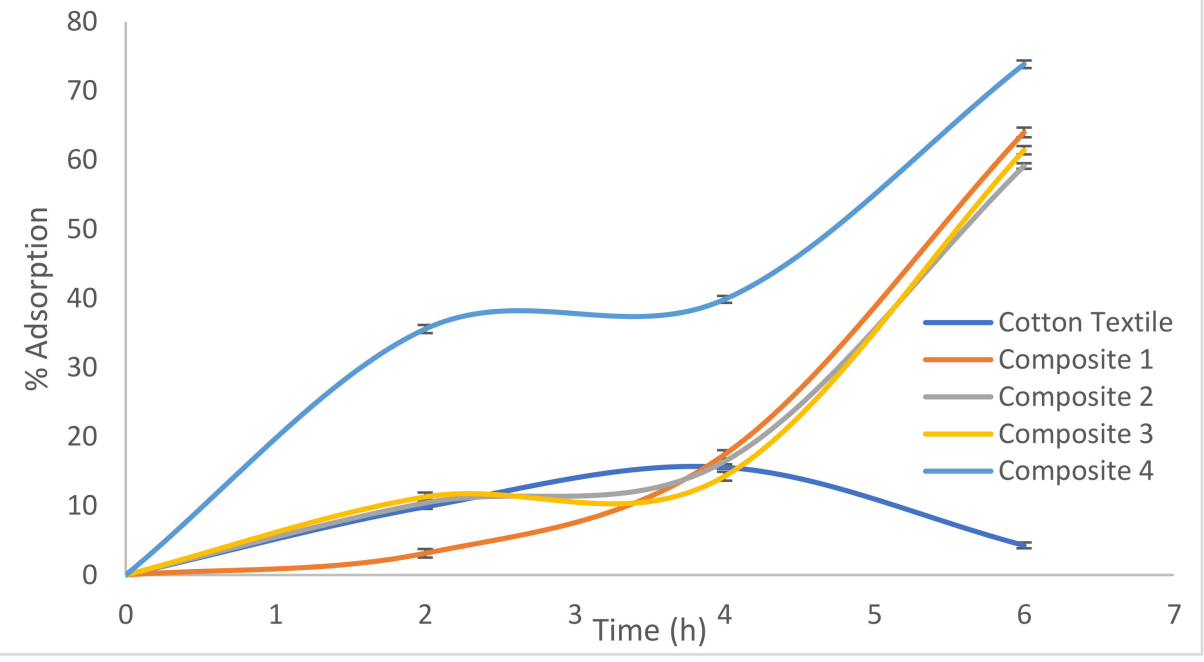

Figure 5. Lead adsorption percentage of composites and cotton textiles in (a) $\mathrm{PbO}$ solution or (b) $\mathrm{Pb}\left(\mathrm{NO}_{3}\right)_{2}$ solution, both at $\mathrm{pH} 5$. 

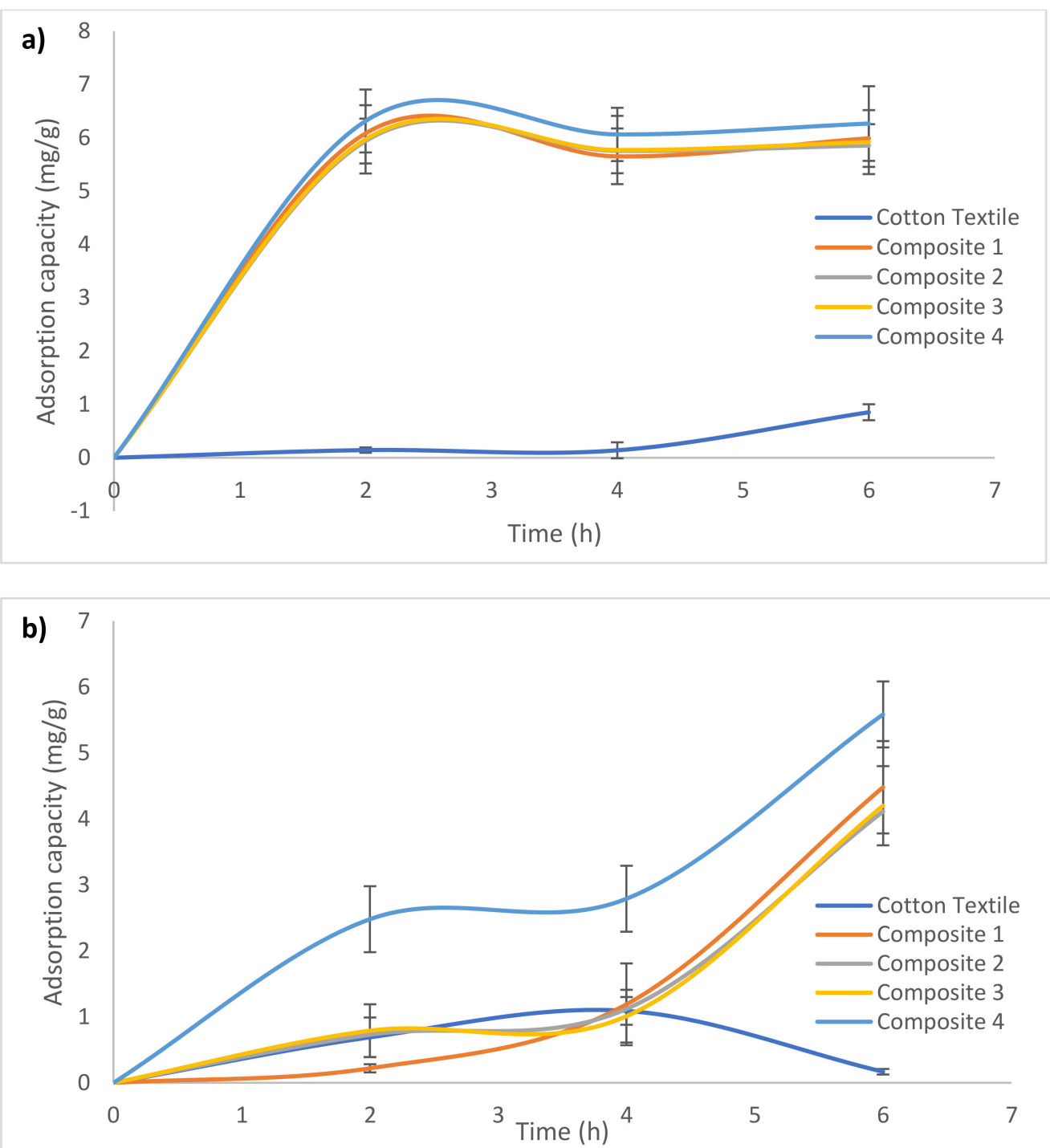

Figure 6. Adsorption capacity of composites and cotton textiles in (a) $\mathrm{PbO}$ solution or (b) $\mathrm{Pb}\left(\mathrm{NO}_{3}\right)_{2}$ solution, both at $\mathrm{pH} 5$. 

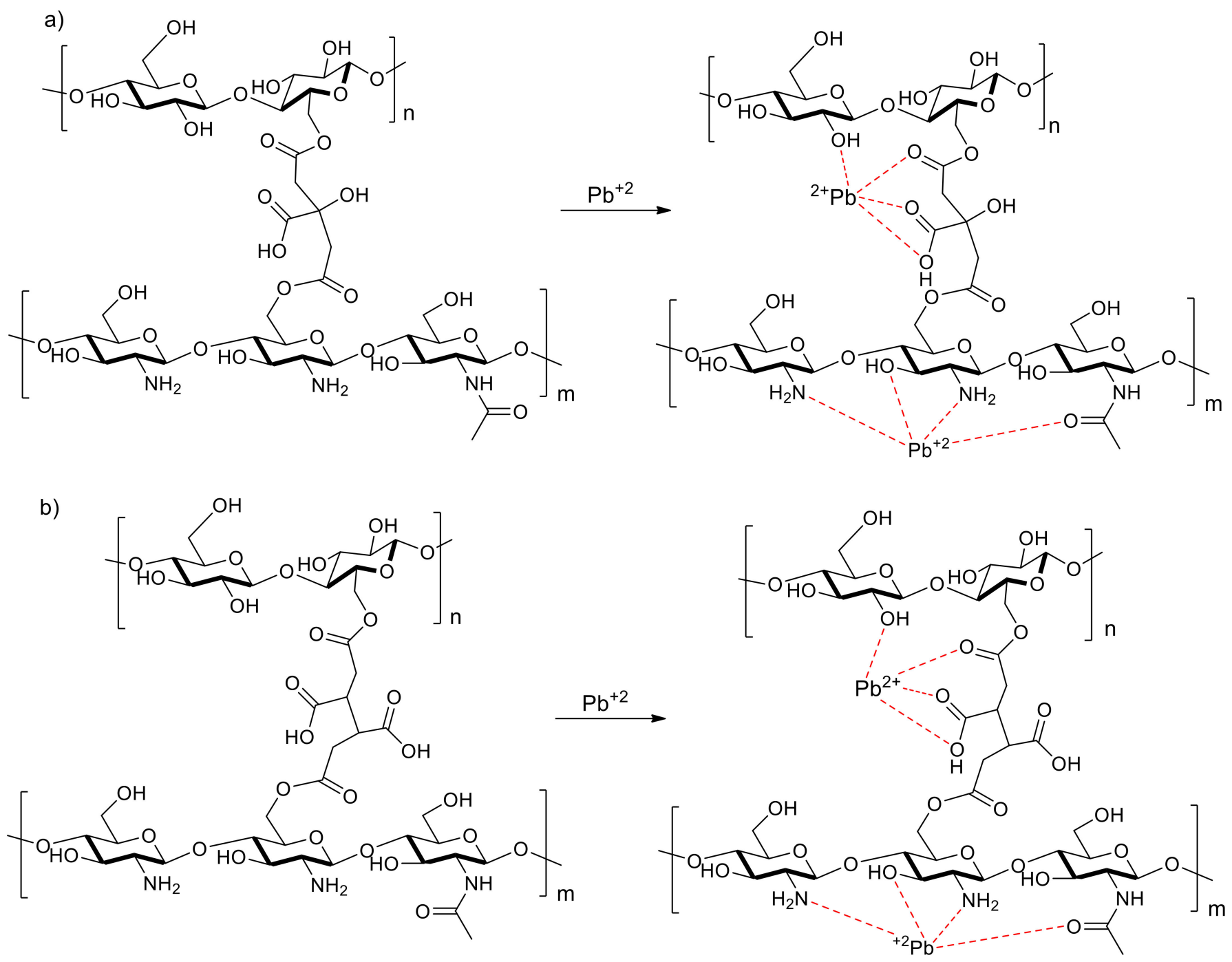

Scheme 1. Proposed crosslinkage of cotton textile-chitosan composites: (a) citric acid as a crosslinker and composite interaction with lead; (b) butanetetracarboxylic acid as a crosslinker and composites' interaction with lead.

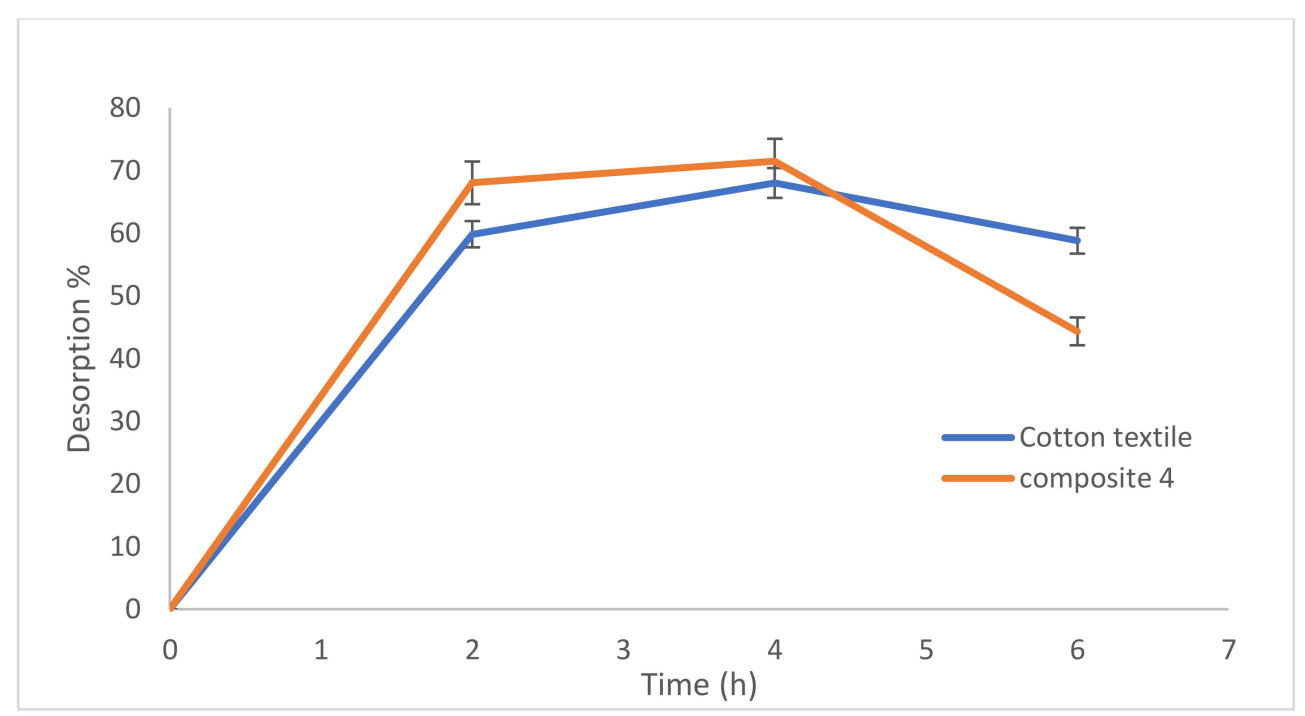

Figure 7. Desorption \% of lead ions with composite 4 and cotton textile in nitric acid solution. 

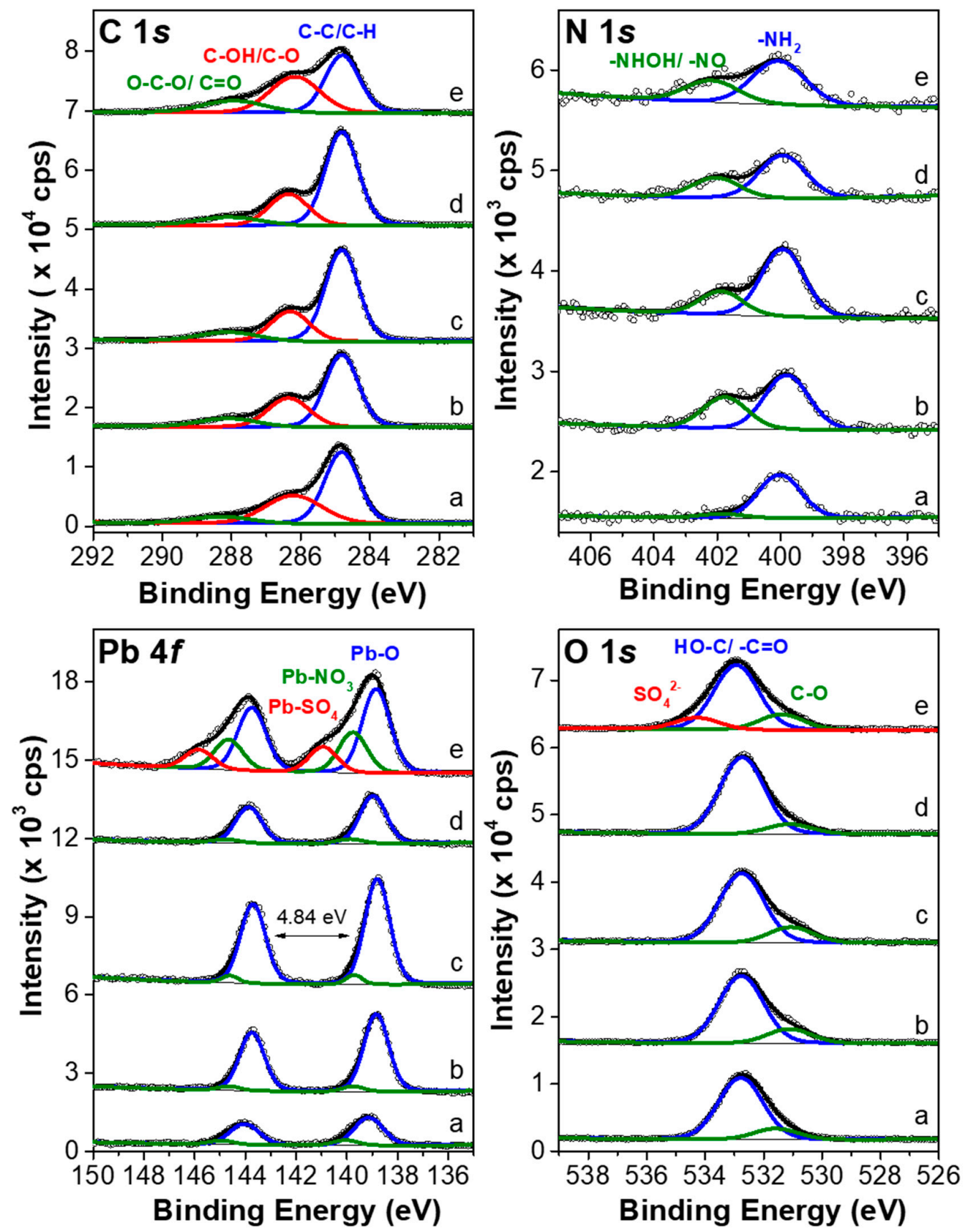

Figure 8. XPS high resolution spectra of core levels of $\mathrm{C} 1 s, \mathrm{~N} 1 s, \mathrm{O} 1 \mathrm{~s}$, and $\mathrm{Pb} 4 f$ for (a) cotton textile, (b) composite 1, (c) composite 3, (d) composite 2, and (e) composite 4.

Table 3. Relative atomic concentration (\%) for the different composites.

\begin{tabular}{|c|c|c|c|c|c|c|c|c|c|c|c|}
\hline Orbital & & C 1s & & & $\mathrm{N} 1 \mathrm{~s}$ & & O 1s & & & $\mathrm{Pb} 4 f$ & \\
\hline Composite & C-C/C-H & $\mathrm{C}-\mathrm{OH} / \mathrm{C}-\mathrm{O}$ & $\begin{array}{c}\mathrm{O}-\mathrm{C}- \\
\mathrm{O} / \mathrm{C}=\mathrm{O}\end{array}$ & $\mathrm{NH}_{2}$ & -NHOH/-NO & $\mathrm{O}-\mathrm{C}$ & $\mathrm{OH}-/ \mathrm{O}=\mathrm{C}-$ & $\mathrm{SO}_{4}{ }^{2-}$ & $\mathrm{Pb}-\mathrm{O}$ & $\mathrm{Pb}-\mathrm{NO}_{3}$ & $\mathrm{~Pb}-\mathrm{SO}_{4}$ \\
\hline $\begin{array}{l}\text { Cotton } \\
\text { textile }\end{array}$ & 43.6 & 27.7 & 7.1 & 1.2 & 0.0 & 16.9 & 3.0 & 0.0 & 0.3 & 0.1 & 0.0 \\
\hline $\begin{array}{l}1 \\
3 \\
2 \\
4\end{array}$ & $\begin{array}{l}43.7 \\
48.8 \\
49.0 \\
31.4\end{array}$ & $\begin{array}{l}21.4 \\
18.5 \\
19.5 \\
29.2\end{array}$ & $\begin{array}{c}8.8 \\
8.4 \\
8.3 \\
12.1\end{array}$ & $\begin{array}{l}1.5 \\
1.6 \\
1.1 \\
1.3\end{array}$ & $\begin{array}{l}0.9 \\
0.6 \\
0.5 \\
0.7\end{array}$ & $\begin{array}{l}18.8 \\
17.2 \\
18.6 \\
16.6\end{array}$ & $\begin{array}{l}4.0 \\
3.9 \\
2.4 \\
4.0\end{array}$ & $\begin{array}{l}0.0 \\
0.0 \\
0.0 \\
3.0\end{array}$ & $\begin{array}{l}0.8 \\
1.0 \\
0.5 \\
0.9\end{array}$ & $\begin{array}{l}0.1 \\
0.1 \\
0.0 \\
0.4\end{array}$ & $\begin{array}{l}0.0 \\
0.0 \\
0.0 \\
0.3\end{array}$ \\
\hline
\end{tabular}




\section{Discussion}

The chitosan content of composites, as determined by an elemental analysis, showed that the use of a catalyst and an oxidizing agent $\left(\mathrm{H}_{2} \mathrm{O}_{2}\right)$ favors chitosan covalent crosslinkage, mainly due to the surface modification of the cotton textile [21,24]. The $\mathrm{H}_{2} \mathrm{O}_{2}$ effect, besides discoloring the cotton textile, relies on the dissociation of perhydroxyl anion $\left(\mathrm{HOO}^{-}\right)$, which predominantly occurs under alkaline conditions; hence, the action takes place when the nucleophile $\left(\mathrm{HOO}^{-}\right)$attacks the carbonyls and conjugated carbonyl groups that comprise the fiber [24,25]. There have been several reports of the chemical crosslinkage of chitosan within the free amino group; nevertheless, the crosslinker, chitosan concentration, catalyst, temperature, and reaction time are factors that affect the reaction site $[5,9,11,12,15-18,21]$. In this case, $\mathrm{R}-\mathrm{OH}$ was more nucleophilic than $\mathrm{R}^{-\mathrm{NH}_{3}}{ }^{+}$, hence $\mathrm{OH}-\mathrm{C}_{6}$ easily participated in nucleophilic reactions.

The adsorption capacity results showed that co-existing ions had adverse effects on the adsorption of lead over CCs. Thus, the presence of coexisting ions determined the adsorption capacity of CCs, which in this case was due to the crosslinkage with carboxylic acids; this can proceed in one of two ways: by chelation between nitrogen atoms of the $\mathrm{NH}_{2}{ }^{-}$groups of chitosan and/or by electrostatic attraction between carboxyl groups of crosslinkers grafted into chitosan and cotton fiber. There are a few reports in which $\mathrm{Pb}$ species could be recognized at high binding energy by XPS analysis. However, carboxylic groups in the composites are responsible for promoting the adsorption of lead due to electronegativity, hence the binding energy found for $\mathrm{Pb}$ species by XPS suggests that the oxidation state of $\mathrm{Pb}$ in these composites was $2+$. In addition, desorption determination confirmed that our composite formulation increased the number of active sites compared to the pristine cotton textile.

This work was an approach to demonstrate the potential ability of chitosan-cotton textile composites, developed with nontoxic reagents, to adsorb pollutants such as lead in water at trace levels. Once adsorbed, the pollutants can be concentrated in smaller quantities of acidic aqueous solution and the composites can be reused and eventually biodegraded.

It is worth mentioning that our research group is working with theoretical calculations to determine the affinity of several heavy metals for these composites, in addition to specifically determining the chemical modification of cellulose and chitosan by this kind of crosslinking processes, to reduce reagent consumption as well as waste generation.

Author Contributions: Conceptualization, methodology, investigation, data curation, most of the validation, writing — original draft preparation, project administration, and funding acquisition: D.A.S. Data curation and investigation: B.C.-G. AFM and SEM analysis, data interpretation, validation and writing: J.M.-A. FTIR analysis, chemical schemes, methodology of MPAES analysis, and draft preparation: L.H.-G. XPS analysis and reviewing of the draft: M.S., R.G.-H. All authors have read and agreed to the published version of the manuscript.

Funding: This research was funded by the National Council for Science and Technology, CONACYT, for the project 247458, and the scholarship for Belén Chamorro with the project 245838.

Institutional Review Board Statement: Not applicable.

Informed Consent Statement: Not applicable.

Data Availability Statement: Not applicable.

Acknowledgments: The authors are grateful to Alberto Toxqui Terán and Luis Silva Vidaurri for their technical assistance with the structural analysis.

Conflicts of Interest: The authors declare no conflict of interest. 


\section{References}

1. Rahman, M.L.; Fui, C.J.; Ting, T.X.; Sarjadi, M.S.; Arshad, S.E.; Musta, B. Polymer Ligands Derived from Jute Fiber for Heavy Metal Removal from Electroplating Wastewater. Polymers 2020, 12, 2521. [CrossRef] [PubMed]

2. Tighadouini, S.; Radi, S.; El Massaoudi, M.; Lakbaibi, Z.; Ferbinteanu, M.; Garcia, Y. Efficient and Environmental Friendly Adsorbent Based on $\beta$-Ketoenol-Pyrazole-Thiophene for Heavy-Metal Ion Removal from Aquatic Medium: A combined Experimental and Theoretical Study. ACS Omega 2020, 5, 17324-17336. [CrossRef] [PubMed]

3. Pathan, S.; Suryasarathi, B. Arsenic removal using "Green” renewable feedstock-based hydrogels: Current and future perspectives. ACS Omega 2018, 3, 5910-5917. [CrossRef] [PubMed]

4. D'Halluin, M.; Rull-Barrull, J.; Bretel, G.; Labrugère, C.; Le Grognec, E.; Felpin, F.X. Chemical Modified Cellulose Filter Paper for Heavy Metal Remediation in Water. ACS Sustain. Chem. Eng. 2017, 5, 1965-1973. [CrossRef]

5. Ferrero, F.; Tonetti, C.; Periolatto, M. Adsorption of chromate and cupric ions onto chitosan-coated cotton gauze. Carbohyd. Polym 2014, 110, 367-373. [CrossRef]

6. Gusmao, K.A.G.; Gurgel, L.V.A.; Melo, T.M.S.; Gil, L.F. Application of succinylated sugarcane bagasse as adsorbent to remove methylene blue and gentian violet from aqueous solutions-Kinetic and equilibrium studies. Dyes Pigments 2012, 92, 967-974. [CrossRef]

7. Luo, J.; Fu, K.; Yu, D.; Hristovski, K.D.; Westerhoff, P.; Crittenden, J.C. Review of Advances in Engineering Nanomaterial Adsorbents for Metal Removal and Recovery from Water: Synthesis and Microstructure Impacts. ACS ESET Eng. 2021, 1, 623-661.

8. Luo, J.; Yu, D.; Hristovski, K.D.; Fu, K.; Shen, Y.; Westerhoff, P.; Crittenden, J.C. Critical Review of Advances in Engineering Nanomaterial Adsorbents for Metal Removal and Recovery from Water: Mechanism Identification and Engineering Design. Environ. Sci. Technol. 2021, 55, 4287-4304. [CrossRef]

9. Nair, V.; Panigrahy, A.; Vinu, R. Development of novel chitosan-lignin composites for adsorption of dyes and metal ions from wastewater. Chem. Eng. J. 2014, 245, 491-502. [CrossRef]

10. Zhang, J.; Wang, A. Adsorption of $\mathrm{Pb}$ (II) from aqueous solution by Chitosan-g-poly (acrylic acid)/Attapulgite/sodium humate composite hydrogels. J. Chem. Eng. D 2010, 55, 2379-2384. [CrossRef]

11. Qu, R.; Sun, C.; Wang, M.; Ji, C.; Xu, Q.; Zhang, Y.; Wang, C.; Chen, H.; Yin, P. Adsorption of Au (III) from aqueous solution using cotton fiber/chitosan composite adsorbents. Hydrometallurgy 2009, 100, 65-71. [CrossRef]

12. Azizkhani, S.; Mahmoudi, E.; Abdullah, N.; Ismail, M.H.S.; Mohammad, A.W.; Hussain, S.A. Synthesis and Characterisation of Graphene Oxide-Silica-Chitosan for eliminating the $\mathrm{Pb}(\mathrm{II})$ from Aqueous Solution. Polymers 2020, 12, 1922. [CrossRef]

13. Yu, D.; Wang, Y.; Wu, M.; Zhang, L.; Wang, L.; Ni, H. Surface functionalization of cellulose with hyperbranched polyamide for efficient adsorption of organic dyes and heavy metals. J. Clean. Prod. 2019, 232, 774-783. [CrossRef]

14. Hashem, A.; Fletcher, A.J.; Younis, H.; Mauof, H.; Abou-Okeil, A. Adsorption of Pb(II) ions from contaminated water by 1,2,3,4-butanetetracarboxylic acid-modified microcrystalline cellulose: Isotherms, kinetics, and thermodynamic studies. Int. J. Biol. Macromol. 2019, 164, 3193-3203. [CrossRef]

15. Yang, H.; Sheikhi, A.; van de Ven, T.G.M. Reusable green aerogels from crosslinked hair nanocrystalline cellulose and modified chitosan for dye removal. Langmuir 2016, 32, 11771-11779. [CrossRef]

16. Schiffman, J.F.; Schauer, C.L. Cross-linking chitosan fibers. Biomacromolecules 2007, 8, 549-601.

17. Zhang, G.; Qu, R.; Changmei, S.; Ji, C.; Chen, H. Adsorption for Metal Ions of Chitosan Coated Cotton Fiber. J. Appl. Polym. Sci. 2008, 110, 2321-2327. [CrossRef]

18. Madala, S.; Nadavala, S.K.; Vudagandla, S.; Boddu, V.M.; Abburi, K. Equilibrium, kinetics and thermodynamics of Cadmium (II) biosorption on to composite chitosan biosorbent. Arab. J. Chem. 2017, 10, S1883-S1893. [CrossRef]

19. Dhanapal, V.; Subramanian, K. Modified chitosan for the collection of reactive blue 4, arsenic and mercury from aqueous media. Carbohyd. Polym. 2015, 117, 123-132. [CrossRef] [PubMed]

20. Nazari, A.; Montazer, M.; Rashidi, A.; Yazdanshenas, M.; Moghadam, M.B. Optimization of cotton crosslinking with polycarboxylic acids and Nano TiO2 using central composite design. J. Appl. Polym. Sci. 2010, 117, 2740-2748. [CrossRef]

21. Alonso, D.; Gimeno, M.; Olayo, R.; Vázquez-Torres, H.; Sepúlveda-Sánchez, J.D.; Shirai, K. Cross-linking chitosan into UVirradiated cellulose fibers for the preparation of antimicrobial-finished textiles. Carbohyd. Polym. 2009, 77, 536-546. [CrossRef]

22. Ghosh, D.T.; Netravali, A. Cross-linked waxy maize starch-based "green" composites. ACS Sustain. Chem. Eng. 2013, 1, 1537-1544. [CrossRef]

23. Alonso, D.; Gimeno, M.; Sepúlveda-Sánchez, J.D.; Shirai, K. Chitosan-based microcapsules containing grapefruit seed extract grafted onto cellulose fibers by non-toxic procedure. Carbohyd. Res. 2010, 354, 854-859. [CrossRef] [PubMed]

24. Shen, C.; Wen, Y.; Kang, X.; Liu, W. H2O2-induced surface modification: A facile, effective and environmentally friendly pretreatment of chitosan for dyes removal. Chem. Eng. J. 2011, 166, 474-482. [CrossRef]

25. Wu, S.J.; Cai, R.Z.; Sun, Y.Y. Degradation of curdlan using hydrogen peroxide. Food Chem. 2012, 135, 2436-2438. [CrossRef]

26. Razak, N.I.A.; Ibrahim, N.A.; Zainuddin, N.; Rayung, M.; Saad, W.Z. The influence of chemical surface modification of kenaf fiber using hydrogen peroxide on the mechanical properties of biodegradable kenaf fiber/poly (lactic acid) composites. Molecules 2014, 19, 2957-2968. [CrossRef]

27. Pearson, R.G. Hard and Soft Acids and Bases, HASB, Part 1: Fundamental Principles. J. Chem. Educ. 1986, 45, 581-587. [CrossRef] 
28. Xu, X.; Yu, J.; Liu, C.; Yang, G.; Shi, L.; Zhuang, X. Xanthated chitosan/cellulose sponges for the efficient removal of anionic and cationic dyes. React. Funct. Polym. 2021, 160, 104840. [CrossRef]

29. Khiari, R.; Rol, F.; Brochier Salon, M.C.; Bras, J.; Belgacem, M.N. Efficiency of Cellulose Carbonates to Produce Cellulose Nanofibers. ACS Sustain. Chem. Eng. 2019, 7, 8155-8167. [CrossRef]

30. Shi, B.; Zhao, C.; Ji, Y.; Shi, J.; Yang, H. Promotion effect of PANI on Fe-PANI/Zeoliteas an active and recyclable Fenton-like catalyst under near-neutral condition. Appl. Surf. Sci. 2020, 508, 145298. [CrossRef]

31. Fras, L.; Johansson, L.S.; Stenius, P.; Laine, J.; Stana-Kleinschek, K.; Ribitsch, V. Analysis of the oxidation of cellulose fibres by titration and XPS. Colloids Surf. A Physicochem. Eng. Asp. 2005, 260, 101-108. [CrossRef]

32. Rouxhet, P.G.; Genet, M.J. XPS analysis of bio-organic systems. Surf. Interface Analysis 2011, 43, 1453-1470. [CrossRef]

33. Zhuang, S.; Zhu, K.; Wang, J. Fibrous chitosan/cellulose composite as an efficient adsorbent for Co(II) removal. J. Clean. Prod. 2021, 285, 124911. [CrossRef]

34. Maachou, H.; Genet, M.J.; Aliouche, D.; Dupont-Gillain, C.C.; Rouxhet, P.G. XPS analysis of chitosan-hydroxyapatite biomaterials: From elements to compounds. Surf. Interface Anal. 2013, 45, 1088-1097. [CrossRef]

35. Samad, H.A.; Watson, P.R. An XPS study of the adsorption of lead on goethitea-FeOOH. Appl. Surf. Sci. 1998, 136, 46-54. [CrossRef]

36. Zheng, Y.X.; Ning, J.L.; Xie, H.; Lv, J.F.; Hu, P.J.; Pang, J. Study on surface modification of cerussite by thermochemical processing with pyrite. Physicochem. Probl. Miner. Process. 2021, 57, 156-167. [CrossRef]

37. Wagner, C.D.; Zatko, D.A.; Raymond, R.H. Use of the Oxygen KLL Auger Lines in Identification of Surface Chemical States by Electron Spectroscopy for Chemical Analysis. Anal. Chem. 1980, 52, 1445-1451. [CrossRef]

38. Marchon, B.; Carrazza, J.; Heinemann, H.; Somorjai, G.A. TPD and XPS studies of O2, CO2, and H2O adsorption on clean polycrystalline graphite. Carbon 1998, 26, 507-514. [CrossRef] 